\title{
Improving The Patient's Experience In The Emergency Department During COVID-19 Pandemic: a community-Based Analysis From Western Saudi Arabia.
}

\author{
Khadijah Banjar and Sharafaldeen Bin Nafisah
}

\begin{abstract}
Background Patient satisfaction is an important measure of the health care encounter. It is challenging to achieve a perfect patient experience during the current COVID-19 pandemic, especially from an emergency department visit. Aim This study aimed to assess the factors that improve patient experience during an emergency department (ED) visit in the western region of Saudi Arabia. Methods This is a cross-sectional study, conducted over a month from January to February 2021. Via an electronic survey tool, we used the Echelle de Qualité des Soins en Hospitalisation (EQS-H) to measure patients' satisfaction with their ED encounter. Results The total level of satisfaction was high in $43.66 \%(n=224)$ of participants, moderate in $37.04 \%(n=190)$, and $19.29 \%(n=99)$ were unsatisfied. We noted significant predictors of dis- satisfaction, including increasing age, higher educational level, and the existence of chronic diseases. A clear treatment plan and discharge instructions were important determinants for improving patient satisfaction. Conclusion The determinants of patient satisfaction during an ED visit are an important quality marker of the emergency department encounter. Such findings should be used as a benchmark for future programs aiming to improve patients' experience during ED visits.
\end{abstract}

Index Terms-Emergency department satisfaction, patient's experience

\section{INTRODUCTION}

Patient satisfaction is an important measure of the health care encounter. Because satisfaction is an outcome of the expectations of, and interactions with, the different components of the healthcare system, [1] an understanding of this experience is crucial in moving toward patient-centred care, clinical effectiveness, patient safety and optimal healthcare system delivery $[2,3]$.

The emergency department plays a pivotal role in providing timely access to acute health care and provides a safety net for primary health care settings. However, the emergency department encounter is unique in that the patient experience is a long process, from triage until being seen by an emer- gency provider. Factors influencing the patient's perception of acute care delivery include the duration of waiting time, the provider's care, assistance for pain relief, cleanliness of the facility, and bed arrangement, among others. Provision of

Khadijah Banjar, Sharafaldeen Bin Nafisah are with Emergency Medicine Department, King Fahad Medical City, Riyadh, Saudi Arabia., e-mail: khadeejahbanjar@hotmail.com, e-mail: sbinnafisah@kfmc.med.sa

Khadijah Banjar is the corresponding author. discharge instructions and follow-up also affect the patient's experience and, subsequently, his/her satisfaction [4-6].

It is challenging to achieve a perfect patient experience during the current COVID-19 pandemic, especially from an emergency department visit. The struggle to meet demand in the face of limited supply can result in patient experience being overlooked. However, an investigation into patient satisfaction during such period is imperative, not only to inform policy change but also to foster a safe environment. Therefore, we aim in this study to quantify the patient's emergency department experience during the COVID-19 pandemic in the western region of Saudi Arabia. We also aim to investigate the factors that improve patient experience during such encounter, and analyse what the patients perceive as important to improve their ED experience. Furthermore, we aim to inquire into the method of discharge instructions deemed appropriate by patients, and whether a follow-up call two days after ED discharge is acceptable.

Methods This is a cross-sectional study, conducted over a month from January to February 2021 in the western region of Saudi Arabia. The western region encompasses the regions of Makkah Al-Mukarramah and Al-Madinah Al-Munawwarah, with a total combined population of $11,273,414$. The total number of COVID-19 cases until the time of writing is 119,987 , with a mortality rate of $2.61 \%$ [7].

We estimated a sample size of 385 using the Raosoft ${ }^{\circledR}$ calculator, with a $5 \%$ level of significance, $5 \%$ margin oferror, $95 \%$ confidence, and expected response distribution of $50 \%$. Via an electronic survey tool, we used the validated Arabic version of Echelle de Qualité des Soins en Hospitalisation (EQS$\mathrm{H})$ to measure patient satisfaction during the ED encounter [8]. The survey measures total satisfaction level, clarity of information provided, and satisfaction with the relationship with staff and ED routine. Responses are categorised as "Poor", "Average", "Good", "Very good" and "Excellent". The survey is included in the supplementary material.

The inclusion criteria were any patients who had had an emergency department encounter during the COVID-19 pandemic. We excluded those who were not in the western region and those who did not complete the survey. SPSS software version 21 was used for data analysis, and we complied with the STROBE guidelines [9] for reporting the data. The study was approved by the ethical committee. 


\section{RESULTS}

Demographics:

The total number of participants in our analysis was 514, with a mean age of 35.6 years old $(\mathrm{SD}=13.35)$. The demographic details are illustrated in Table 1.

Level of satisfaction:

An investigation into the level of satisfaction revealed ahigh satisfaction level in $43.66 \% \quad(\mathrm{n}=224)$ of participants. A moderate satisfaction level was noted in $37.04 \%(\mathrm{n}=190)$ of participants, while $19.29 \%(\mathrm{n}=99)$ were unsatisfied. Further analysis revealed that the discharge instruction component had a higher level of dissatisfaction. Likewise, instructions about possible side effects, what to avoid and what symptoms to expect, appeared to have an increased level of dissatisfaction compared to other unsatisfactory components. A detailed description of each of the satisfaction components is included in Table 2.

Satisfaction with clarity of information provided in the ED and relationship with staff and ED routine:

$48.93 \%(n=251)$ of participants were highly satisfied with the clarity of information, $33.14 \%(\mathrm{n}=170)$ were moderately satisfied and $17.93 \%(n=92)$ were unsatisfied. Regarding the relationship with staff and ED routine, 38.4\% $(n=197)$ were highly satisfied, $36.65 \%(\mathrm{n}=188)$ were moderately satisfied and $24.85 \%(\mathrm{n}=128)$ were unsatisfied.

Predictors of satisfaction:

-Age:

An investigation of the association between age and satisfaction revealed a negative correlation. Such negative correlation was also noted with the clarity of the information provided; $\mathrm{r}=$ $0.156, \mathrm{n}=508, \mathrm{p}<0.05$, the relationship with staff and ED routine; $\mathrm{r}=-0.159, \mathrm{n}=508, \mathrm{p}<0.05$, and the total satisfaction level; $\mathrm{r}=-0.16, \mathrm{n}=508, \mathrm{p}<0.05$. This indicates that the older the patient was, the less their perception of clarity of the information provided in the ED was. Similarly, the older the patient was, the less satisfied they were with the relationship with staff and the ED routine, and therefore the less overall satisfaction they experienced from their ED encounter.

-Education level:

The level of education revealed a significant difference with regard to the total satisfaction, clarity of information, and relationship with staff and ED routine. The percentages and the SD of each component are illustrated in Table 3. It appears that, the higher the educational level, the lower the satisfaction becomes, with a lower perception of the clarity of information provided in the ED, and even less satisfaction with the relationship with staff and the ED routine.

-Patients with chronic disease(s):

There is a significant difference in scoring of the clarity of information provided between those with chronic dis- eases $(\mathrm{M}=17.87, \mathrm{SD}=4.33)$ and those who are medically free $(\mathrm{M}=18.95, \mathrm{SD}=4.91) ; \mathrm{t}(510)=-2.27, \mathrm{p}<0.05$. Another significant association was noted in the scores for the explanation of the aims of the treatment (medication, operation, etc) for this segment $(\mathrm{M}=3.72, \mathrm{SD}=1.07)$ vs $(\mathrm{M}=3.95, \mathrm{SD}=1.08)$; $\mathrm{t}(510)=-$ $2.16, \mathrm{p}<0.05$. Explanation of the possible treatment side effects was scored as less satisfactory in those with chronic diseases:
$(\mathrm{M}=2.93, \mathrm{SD}=1.3)$ vs $(\mathrm{M}=3.35, \mathrm{SD}=1.44) ; \mathrm{t}(5263.79)=-3.13$, $\mathrm{p}<0.05$.

Explanation of the symptoms that should be watched for in the future was also scored as less satisfactory in patients with chronic diseases $(\mathrm{M}=3.24, \mathrm{SD}=1.21)$ than in those who are medically free $(\mathrm{M}=3.53, \mathrm{SD}=1.25) ; \mathrm{t}(510)=-2.3, \mathrm{p}<0.05$. They also reported less involvement in the decision concerning their health $(\mathrm{M}=3.52, \mathrm{SD}=1.27)$ than those without chronic diseases $(\mathrm{M}=3.78, \mathrm{SD}=1.22) ; \mathrm{t}(510)=-216, \mathrm{p}<0.05$

-A clear treatment plan:

We investigated the association between satisfaction and the provision of a clear treatment plan. There was a significant difference in the total satisfaction scores. Those who received a clear treatment plan had a higher satisfaction level $(\mathrm{M}=64.65$, $\mathrm{SD}=11.54)$ than those who did not $(\mathrm{M}=47.94, \mathrm{SD}=14.54)$; $\mathrm{t}(255.83)=12.85, \mathrm{p}<0.05$. Moreover, a significant difference is noted in the scoring of clarity of information by those who received such a plan $(M=20.19, S D=3.94)$ and those who did not $(\mathrm{M}=15.34, \mathrm{SD}=4.79) ; \mathrm{t}(262.62)=11.22, \mathrm{p}<0.05$.

The scores for relationship with staff and ED routine were also consistent with such findings: $(\mathrm{M}=44.46, \mathrm{SD}=8.36)$ vs $(\mathrm{M}=32.59, \mathrm{SD}=10.65) ; \mathrm{t}(262.62)=11.22, \mathrm{p}<0.05$.

-Discharge instructions:

Participants reported a higher preference for two formats of discharge instructions: verbal and/or written in comparison to other methods. Table 4 illustrates the percentage with a preference for each method. The preferred format of discharge instructions varies according to age, with electronic methods preferred in the 26-35-year age group, and written instructions preferred by those $36-45$ years of age. Verbal methods were preferred by those 45 years old and older. However, a combined format was consistently advocated among the different age groups; Linear-by-Linear association $(1)=0.71, p<0.05$.

-Follow-up communication after ED discharge:

The majority of the participants preferred to have a followup two days after discharge from the ED: $93.2 \%(n=479)$. The participants' overall opinion about the care and treatment they received differed between those who advocated having a follow-up call $(\mathrm{M}=3.67, \mathrm{SD}=1.16)$ and those who did not advocate such follow-up $(\mathrm{M}=4, \mathrm{SD}=0.82)$. This indicates that a follow-up call might bridge the deficiency in perceived satisfaction. From 35 years and older, there is a consensus for the need for follow-up communication. Younger age groups, on the other hand, did not reach such consensus, Linear-by- Linear association $(1)=9.81, \mathrm{p}<0.05$.

Although gender did not influence the preference for followup, $p>0.05$, we noted that unmarried participants were more reluctant to have follow-up communication than those who are married: $37.4 \%$ and $62.6 \%$ respectively, $\mathrm{X} 2=5.28(1), \mathrm{p}<0.05$.

\section{DISCUSSION}

Until the time of writing, this is the first study to analyse patient experience and satisfaction in the emergency department during COVID-19 in Saudi Arabia. The satisfaction scores revealed that $43.66 \%$ of participants were highly satisfied with the ED service despite the pandemic. Such a percentage is higher than a percentage reported from a central region prior to 
the COVID-19 pandemic, in which only $32.8 \%$ shared similar satisfaction [10]. In line with that, when we compare the level of dissatisfaction, we note a lower level than in the central region analysis: $19.29 \%$ and $26.7 \%$ respectively [10].

Elderly patients demonstrate less satisfaction across all the satisfaction components. They appear less satisfied with the information provided, indicating a need to spend more time with them. Not knowing their treating physician, violation of their privacy, eating and dressing difficulties, and nurses not spending enough time helping them, all negatively impacted their experience.

Patients with chronic diseases reported satisfaction scores that are concerning for being stigmatised. This group was significantly less satisfied with the explanation of their symptoms, the explanation of possible side effects of medications used, and the explanation of what to monitor after discharge. They also reported not having their opinion heard in their treatment plan. Such findings indicate a prejudice toward such patients, holding them to blame for their chronic disease - a phenomenon of chronic diseases stigma.

Health empowerment and expectations increased with a higher educational level $[10,11]$. This was apparent in our analysis, in which a higher educational level was associated with less satisfaction with the information provided and with the relationship with staff and ED routine, and a lower overall satisfaction level. Therefore, any future quality improvement programs should not overlook the opinion of those with higher education levels.

In particular, a clear treatment plan was associated with higher satisfaction levels across all the components. Although the treatment plan often is not consistent in the ED, given the progress of the disease, the wide differential diagnosis and the objective and subjective clinical sense. Nonetheless, an initial explanation of the steps of investigation and continuously updating the patients should suffice.

Furthermore, discharge instructions are an integral part of the ED management. Although a combined method is preferred, verbal and or written material is advocated by the majority of the patients. Such findings align with the previous study in which a combined method was more effective [12]. Finally, 93.2\% supported having a follow-up communication with the ED after two days from discharge. Such practice, although common in the paediatric emergency department, should also be adapted for the adult. It also prudent to inform the patient about his/her preference for a follow-up communication as we noted unmarried people were reluctant toward a follow-up communication.

The limitation of this analysis lies in that the number of females and in particular married ones outweigh males. Such findings might threaten the generalizability; yet an investigation of gender effect did not demonstrate a difference among the various domains of satisfaction, $p>0.05$. Moreover, the discharge method did not differ between males and females and married vs non-married, $\mathrm{p}>0.05$

\section{CONCLUSION:}

Patient's experience and satisfaction should be a benchmark for monitoring the quality of the emergency care provided.
This article pleads for focusing more on the elderly group in educating them and ensuring the information provided is clear. Chronic diseases, on the other hand, should not trigger prejudice and stigmatisation. Those patients are in need for having a clear information, a shared decision making, and a good discharge instruction given their frequent ED encounter. Providing a clear treatment plan should be a norm taking into consideration the progress of the patient's conditions and the respond to management. We advocate incorporating a followup call after the ED discharge as part of the adult emergency medicine practice.

\section{REFERENCES}

[1] King Faisal Research Specialist. Patient Experience Measurement [Internet]. Available from: https://www.kfshrc. edu.sa/en/home/kfshexperience/measurement

[2] Harrison R, Walton M, Manias E, Mears S, Plumb J. Patients' experiences in Australian hospitals: a systematic review of evidence. Aust Health Rev. 2017 Aug;41(4):419435. doi: 10.1071/AH16053. PMID: 27537609.

[3] Doyle C, Lennox L, Bell D. A systematic review of evidence on the links between patient experience and clinical safety and effectiveness. BMJ Open. 2013 Jan 3;3(1):e001570. doi: 10.1136/bmjopen-2012-001570. PMID: 23293244; PMCID: PMC3549241.

[4] Ministry of Health - Kingdom of Saudi Arabia. Patient Experience Measurement Program [Internet]. Available from: https://www.moh.gov.sa/en/Ministry/pxmp/Pages/default.aspx

[5] Swallmeh E, Byers V, Arisha A. Informing quality in emergency care: understanding patient experiences. Int JHealth Care Qual Assur. 2018 Aug 13;31(7):704-717. doi: 10.1108/IJHCQA-03-2017-0052. PMID: 30354881.

[6] Cetin-Sahin D, Ducharme F, McCusker J, Veillette N, Cossette S, Vu TTM, Vadeboncoeur A, Lachance PA, Mah R, Berthelot S. Experiences of an Emergency Department Visit Among Older Adults and Their Families: Qualitative Findings From a Mixed-Methods Study. J Patient Exp. 2020 Jun;7(3):346-356. doi: 10.1177/2374373519837238. Epub 2019 Apr 8. PMID: 32821794; PMCID: PMC7410141.

[7] Platform TACV. No. Corona statistics in Saudi Arabia by cities and regions Title [Internet]. 2021. Available from: $h$ ttps://corona-v.com/

[8] Soufi G, Belayachi J, Himmich S, Ahid S, Soufi M, Zekraoui A, Abouqal R. Patient satisfaction in an acute medicine department in Morocco. BMC Health Serv Res. 2010 Jun 2;10:149. doi: 10.1186/1472-6963-10-149. PMID: 20525170; PMCID: PMC2900260.

[9] von Elm E, Altman DG, Egger M, Pocock SJ, Gøtzsche PC, Vandenbroucke JP; STROBE Initiative. The Strengthening the Reporting of Observational Studies in Epidemiology (STROBE)statement: guidelines for reporting observational studies. J Clin Epidemiol. 2008 Apr;61(4):344-9. PMID: 18313558

[10] Abolfotouh MA, Al-Assiri MH, Alshahrani RT, Almutairi ZM, Hijazi RA, Alaskar AS. Predictors of patient satisfaction in an emergency care centre in central Saudi 
Arabia: a prospective study. Emerg Med J. 2017 Jan;34(1):2733. doi: 10.1136/emermed-2015-204954. Epub 2016 Aug 1. PMID: 27480456; PMCID: PMC5256124.

[11] Raghupathi V, Raghupathi W. The influence of education on health: an empirical assessment of OECD countries for the period 1995-2015. Arch Public Health. 2020 Apr 6;78:20. doi: 10.1186/s13690-020-00402-5. PMID: 32280462; PMCID: PMC7133023.

[12] Al-Harthy N, Sudersanadas KM, Al-Mutairi M, Vasudevan S, Bin Saleh G, Al-Mutairi M, Hussain LW. Ef- ficacy of patient discharge instructions: A pointer toward caregiver friendly communication methods from pediatric emergency personnel. J Family Community Med. 2016 SepDec;23(3):155-60. doi: 10.4103/2230-8229.189128. PMID: 27625582; PMCID: PMC5009885.

\section{Supplementary material:}

Arabic version of the survey

Table 1. The demographic details of the participants.

\begin{tabular}{|l|l|}
\hline \begin{tabular}{|l|} 
DEMOGRAPHICS \\
Male
\end{tabular} & Percent \% (n) \\
\hline $\begin{array}{l}\text { Female } \\
\text { Marital status }\end{array}$ & $27.7(142)$ \\
\hline Married & $72.7(371)$ \\
\hline Unmarried & $61.1(314)$ \\
\hline $\begin{array}{l}\text { Chronic diseases } \\
\text { Yes }\end{array}$ & $38.7(199)$ \\
\hline No & $26.7(137)$ \\
\hline $\begin{array}{l}\text { Education } \\
\text { Less than high school }\end{array}$ & $73.0(375)$ \\
\hline High school & $4.3(22)$ \\
\hline Diploma & $17.7(91)$ \\
\hline Bachelor & $12.1(62)$ \\
\hline Master and Higher & $58.4(300)$ \\
\hline
\end{tabular}

Table 2. The satisfaction variables

\begin{tabular}{|l|l|l|l|l|l|}
\hline Scale & Poor (n) \% & $\begin{array}{l}\text { Average \% } \\
\text { (n) }\end{array}$ & $\begin{array}{l}\text { Good } \\
\text { (n) }\end{array}$ & $\begin{array}{l}\text { Very Good } \\
\text { (n) \% }\end{array}$ & $\begin{array}{l}\text { Excellent } \\
\text { (n) \% }\end{array}$ \\
\hline How clear were the explanations & & & & & \\
\hline About my symptoms & $3.3(17)$ & $8.8(45)$ & $22.4(115)$ & $37.9(195)$ & $27.4(141)$ \\
\hline $\begin{array}{l}\text { About why I needed certain examinations } \\
\text { or tests }\end{array}$ & $3.7(19)$ & $8.2(42)$ & $22.4(115)$ & $34.0(175)$ & $31.5(162)$ \\
\hline $\begin{array}{l}\text { About the results of my examinations or } \\
\text { tests }\end{array}$ & $3.1(16)$ & $5.4(28)$ & $21.4(110)$ & $34.2(176)$ & $35.6(183)$ \\
\hline $\begin{array}{l}\text { About the aims of my treatment } \\
\text { (medication, operation, etc) }\end{array}$ & $4.1(21)$ & $6.2(32)$ & $20.4(105)$ & $34.4(177)$ & $34.6(178)$ \\
\hline \begin{tabular}{l|l|l|l|} 
About possible side effects of my treatment \\
The hospital staff and the ward; How satisfied were you with the following?
\end{tabular} & $19.1(98)$ & $10.5(54)$ & $21.8(112)$ & $24.3(125)$ & $24.1(124)$ \\
\hline $\begin{array}{l}\text { The information as to which doctor was in } \\
\text { charge of me }\end{array}$ & $6.2(32)$ & $7.4(38)$ & $23.9(123)$ & $30.2(155)$ & $32.1(165)$ \\
\hline Efforts to ensure my privacy & $3.3(17)$ & $6.8(35)$ & $13.6(70)$ & $23.2(119)$ & $52.9(272)$ \\
\hline $\begin{array}{l}\text { Assistance given me for day-to-day } \\
\text { activities (eating, dressing etc) }\end{array}$ & $7.2(37)$ & $10.1(52)$ & $23.3(120)$ & $29.6(152)$ & $29.6(152)$ \\
\hline Assistance for pain relief & $3.3(17)$ & $4.7(24)$ & $19.3(99)$ & $33.3(171)$ & $39.3(202)$ \\
\hline $\begin{array}{l}\text { The promptness of nurses in coming when } \\
\text { called }\end{array}$ & $8.6(44)$ & $8.8(45)$ & $22.4(115)$ & $27.4(141)$ & $32.7(168)$ \\
\hline The organisation of the ward & $6.2(32)$ & $9.9(51)$ & $26.3(135)$ & $30(154)$ & $27.4(141)$ \\
\hline
\end{tabular}




\begin{tabular}{|c|c|c|c|c|c|}
\hline The atmosphere in the ward & $4.1(21)$ & $9.5(49)$ & $26.3(135)$ & $30.9(159)$ & $29.0(149)$ \\
\hline $\begin{array}{l}\text { The readiness of nurses to spend time with } \\
\text { me }\end{array}$ & $6(31)$ & $11.7(60)$ & $22.6(116)$ & $32.1(165)$ & $27.4(141)$ \\
\hline \multicolumn{6}{|c|}{ Information given to me when leaving the hospital; How clear were the explanations? } \\
\hline $\begin{array}{l}\text { About the symptoms I should watch for in } \\
\text { the future }\end{array}$ & $9.9(51)$ & $11.1(57)$ & $27.4(141)$ & $27.4(141)$ & $23.9(123)$ \\
\hline $\begin{array}{l}\text { About the activities I could resume after } \\
\text { discharge (job, sport, etc) }\end{array}$ & $12.5(64)$ & $11.7(60)$ & $23.7(122)$ & $27.2(140)$ & $24.7(127)$ \\
\hline about my medical care after discharge & $6.2(32)$ & $8.9(46)$ & $24.5(126)$ & $29.6(152)$ & $30.5(157)$ \\
\hline \multicolumn{6}{|l|}{ Your overall opinion } \\
\hline $\begin{array}{l}\text { I had as much say as I wanted in medical } \\
\text { decisions that concerned me }\end{array}$ & $7.6(39)$ & $9.3(48)$ & $21.2(109)$ & $27.4(141)$ & $34.2(176)$ \\
\hline $\begin{array}{l}\text { On the whole, the care and treatment that I } \\
\text { received was.... }\end{array}$ & $6(31)$ & $7.8(40)$ & $25.9(113)$ & $31.7(163)$ & $28.4(146)$ \\
\hline
\end{tabular}

Table 3. The various educational level in relation to the domains of satisfaction.

\begin{tabular}{llll}
\hline Educational level & Total satisfaction & $\begin{array}{l}\text { Clarity of information } \\
\text { domain }\end{array}$ & $\begin{array}{l}\text { Relationship with the } \\
\text { ECC staff domain }\end{array}$ \\
\hline $\begin{array}{l}\text { Less than high school } \\
\text { Mean (SD) }\end{array}$ & $62.23(11.26)$ & $19.91(2.76)$ & $42.31(9.49)$ \\
\hline $\begin{array}{l}\text { high school } \\
\text { Mean (SD) }\end{array}$ & $63.32(14.12)$ & $19.67(4.81)$ & $43.65(9.86)$ \\
\hline $\begin{array}{l}\text { Diploma } \\
\text { Mean (SD) }\end{array}$ & $59.89(13.83)$ & $18.69(4.47)$ & $41.19(9.93)$ \\
\hline $\begin{array}{l}\text { Bachelor } \\
\text { Mean (SD) }\end{array}$ & $59.01(14.99)$ & $18.62(4.83)$ & $40.39(10.82)$ \\
\hline $\begin{array}{l}\text { Master and higher } \\
\text { Mean (SD) }\end{array}$ & $50.74(14.27)$ & $15.87(4.79)$ & $34.87(10.92)$ \\
\hline $\begin{array}{l}\text { Statistical significance, } \\
\text { p-value }\end{array}$ & $\mathrm{F}(4,508)=5.33, p<0.05$ & $\mathrm{~F}(4,508)=4.77, p<0.05$ & $\mathrm{~F}(4,508)=4.95, p<0.05$ \\
\hline
\end{tabular}

Table 4. The various methods of discharge instructions preferred by the patients.

\begin{tabular}{|l|l|}
\hline Discharge instructions & Percent \% (n) \\
\hline Verbal communication & $37.5(193)$ \\
\hline Written Discharge instructions & $13.8(71)$ \\
\hline Verbal Communication and written & $41.8(215)$ \\
\hline Electronic & $0.2(1)$ \\
\hline Inform them as appropriate to their case & $0.2(1)$ \\
\hline Combined methods & $0.6(3)$ \\
\hline
\end{tabular}

